\title{
O FENÔMENO DA INFÂNCIA FACE AOS ESPAÇOS FANTASMAGÓRICOS DA METRÓPOLE
}

Paulo Victor de Albuquerque Silva

\begin{abstract}
RESUMO
Esse artigo detém como fonte de pesquisa a relação que se gera de forma diária entre o mundo feérico da vida infantil e as argúcias fantasmagóricas das metrópoles contemporâneas. Para tanto partiremos das análises benjaminianas em torno do horizonte estético, que abarca a faculdade mimética, o mundo lúdico, o fenômeno fantasmagórico e a temporalidade do inferno. Utilizar-se-á, majoritariamente, a obra das "Passagens" e "Reflexões sobre a criança, o brinquedo e a educação", como principal arcabouço da pesquisa. Tem-se por objetivo compreender de que modo se gera o confronto direto entre o fenômeno da metrópole e o olhar feérico da criança através da brincadeira.
\end{abstract}

Palavras-chave: Fantasmagoria. Criança. Temporalidade infernal. Brincadeira.

\section{THE PHENOMENON OF CHILDHOOD FRONT OF THE PHANTASMAGORIC SPACES OF THE METROPOLIS}

\begin{abstract}
This article holds as a research source the relation that is daily generated between the fey world of childhood life and the phantasmagoric acumen of contemporary metropolis. Therefore, first of all, it will be considered the benjaminian analysis about the aesthetic horizon that covers the mimetic faculty, the playful world, the phantasmagoric phenomenon and the temporality of hell. It shall be used, mostly, the opus "Das Passagen-Werk" (The Arcades Project) and "Reflections", as the main outline of the research. The objective is to comprehend how is generated the direct confrontation between the metropolis phenomenon and the child fey view through the play. Key-words: Phantasmagoric, Child, Infernal, Temporality, Play
\end{abstract}




\section{Espaços fantasmagóricos da metrópole}

As obras benjaminianas se debruçam sobre as mais variadas épocas da humanidade devido à grande preocupação de nosso autor com os acontecimentos históricos. Entre elas podemos encontrar dois momentos em que Benjamin demonstrou sua maior atenção, o período barroco do século XVII e o pósmodernismo de seu tempo a partir do século XIX. Nesse instante nos vincularemos às investigações referentes ao século $\mathrm{XIX}$ e início do século $\mathrm{XX}$ tendo em vista compreender o fenômeno da metrópole, para tanto temos como principal fonte de pesquisa a obra das "Passagens".

Já na Exposé de 1939 previamente a sua morte em 1940, Benjamin decide escrever uma introdução ao fragmento Paris, Capital do Século XIX, onde expressa sua concepção de que o curso do mundo histórico agora se manifesta enquanto fatos congelados no formato de coisas. Nesse sentido fica-nos evidente que o aparato simbólico construído historicamente perpassa nossa existência não somente enquanto uma ideia, mas também na objetivação do mundo fenomênico efetivandose na concretude do Real. Todos os resíduos esparramados no século XIX que rastreiam as nuanças da história humana Benjamin as denomina de "A História da Civilização" (Kulturgeschichte), que nada mais são do que registros pontuais fragmentados que expressam toda a carga inerente ao contingente temporal da humanidade, onde através desses objetos podemos reconhecer nossa riqueza construída até o presente. Todo esse aparato revela-se não de maneira ofuscada, opaca ou oculta, ela está à luz do dia, poderíamos dizer de forma até mesmo muito reluzente, mas todo esse esplendor desvela-se sob um luxo fantasmagórico.

\footnotetext{
Nossa pesquisa procura mostrar como, em consequência dessa representação coisificada da civilização, as formas de vida nova e as novas criações de base econômica e técnica, que devemos ao século XIX, entram no universo de uma fantasmagoria ${ }^{1}$.
}

Nesse sentido vemos surgir uma transposição ideológica guiada à materialidade sensível, onde a superfície fenomênica passa por um processo de "iluminação" que faz reluzir os objetos mercadológicos, agora guardados e acolhidos pela espacialidade fantasmagórica.

\footnotetext{
${ }^{1}$ BENJAMIN, p: 53, 2009.
}

Paulo Victor de Albuquerque Silva - Mestrando em Filosofia (UECE), Professor efetivo do Município de Fortaleza. Brasileiro, residente em Fortaleza - CE, E-mail: pvictorpv@ hotmail.com 
Quando nos remetemos aos estudos referentes ao século XVII esboçadas na Origem do Drama Barroco Alemão, Benjamin discorrerá sobre este período tomando como referência a construção estética daquela época, debruçando-se em torno das ruínas presentes nas estruturas artísticas barrocas. Já neste período evidencia-se o olhar de nosso autor em torno dos objetos sensíveis enquanto manifestações do imaginário de um tempo histórico. Essa noção abrangente que leva em consideração todas as faculdades humanas, sejam aquelas alusivas ao plano do distinto ou mesmo do sensível, são transportadas ao século XIX para a investigação dos bens materiais edificados pelo espírito humano dos seres contemporâneos. Se antes a arte barroca utilizava ferramentas alegóricas para expressar a sua linguagem temporal, agora, no mundo capitalista, vimos o brotar do aparato fantasmagórico enquanto constituição da espacialidade do século XIX. A fantasmagoria é a nova configuração do mundo contemporâneo que transformou tanto a vida espacial quanto temporal, tendo como pano de fundo a alienação do homem de seu tempo que passou a desconhecer o modo como as mercadorias passaram a ser construídas e acopladas à realidade social, dando a impressão de composição de um novo habitat. O ferro, o vidro, as luminárias, cada detalhe das passagens parisienses surgem perante o observador como toques de mágica, que estão ali para transporta-lo ao maravilhoso mundo feérico da terra do nunca do capital, nela ninguém pode envelhecer, pois todos se tornam consumidores.

Assim apresentam-se as 'passagens', primeiras formas de aplicação da construção em ferro; (...) na mesma ordem de fenômenos, a experiência do flâneur, que se abandona às fantasmagorias do mercado ${ }^{2}$.

A fantasmagoria detém a capacidade de acoplar ao seu espaço os variados elementos provenientes do aparato técnico industrial, recolhendo em um único ambiente o encontro erótico entre o orgânico e o inorgânico ${ }^{3}$.

\footnotetext{
Ibidem, p: $53-54$.

3 Mario Perniola em sua obra "O Sex Appeal do Inorgânico" irá criar o conceito de "sexualidade neutra" para diferenciar a relação sexual entre as entidades orgânicas e inorgânicas, que por sua vez, não se realiza em uma escala crescente até o encontro do orgasmo iminente, antes permanece em uma linearidade neutra do prazer sexual. Para mais vide: PERNIOLA, Mario. O sex appeal do inorgânico. Tradução de Nilson Moulin. São Paulo: Studio Nobel, 2005.
} 
Vale salientar que os territórios fantasmagóricos da metrópole são conquistas tanto do espaço material quanto espiritual. Os novos ambientes da metrópole acarretam uma mudança integral na espécie humana, que perpassa nosso comportamento, percepções, afecções e fisiologia. Neste sentido vemos surgir à ideia do intérieur, o fenômeno da vida contemporâne, em que o indivíduo se encontra em uma existência autossuficiente, em um habitat próprio e segregado, característica do isolamento do homem atual, sendo em meio a este recinto-cenário que surgem os rastros deixados pelo residente. O fantasma criado pelo "Capetalismo" arquiteta um espaço carregado de uma temporalidade do inferno em que nada deixa escapar, obrigando-nos a segregação de nossa existência em que a produção de uma vida mais autentica no máximo poderá ser o cultivo de novos rastros. Essa possessão demoníaca da metrópole fantasmagórica sufoca a existência humana através de seu ritmo ininterrupto do maquinário cúmplice do capital, onde todos os aparatos descritos por Benjamin no trabalho das "Passagens" como as exposições universais, o intérieur, a experiência do flâneur, a moda, etc., servem como espécies de tentáculos que envolvem os indivíduos em uma atmosfera que estorva uma percepção para além de seu horizonte territorial.

O fenômeno fantasmagórico foi levado ao seu extremo quando passamos a pensá-lo enquanto uma manifestação cósmica com Louis Auguste Blanqui. Mesmo sendo um crítico ferrenho das argúcias elaboradas pelo sistema capitalista de produção, Blanqui constrói sua teoria do "eterno retorno das coisas" tomando emprestado alguns elementos dos estudos físico-químicos, afirmando que por conta da finita quantidade de substâncias presentes na natureza suas combinações tenderiam a se repetir em um ciclo permanente de movimento, sempre da mesma maneira. "A especulação cósmica de Blanqui comporta o ensinamento segundo o qual a humanidade será tomada por uma angústia mítica enquanto a fantasmagoria aí ocupar lugar". ${ }^{4}$ Para Benjamin o pensamento do francês seria a última instância do adágio fantasmagórico formulado no século XIX, pois, através dele, todo o universo passaria a ganhar uma conotação espectral, o que para o autor alemão seria uma visão do inferno. Até mesmo o espírito revolucionário de Blanqui não

\footnotetext{
4 Ibidem, p: 54.

Paulo Victor de Albuquerque Silva - Mestrando em Filosofia (UECE), Professor efetivo do Município de Fortaleza. Brasileiro, residente em Fortaleza - CE, E-mail: pvictorpv@ hotmail.com
} 
resistiria às maquinações do capital através de suas delimitações presidiárias do espaço infernal, que Ihe mantiveram encarcerado não somente no forte de Taureau, como também agrilhoaram as arestas de sua alma.

É nesse contexto que encontraremos atrelado ao aparato fantasmagórico o ideal de progresso histórico da humanidade, cuja crítica pode muito bem ser expresso, para Benjamin, através do quadro de Paul Klee intitulado "Angelus Novus". Com essa imagem nosso autor irá expor sua $9^{\text {a }}$ tese de "Sobre o conceito da história", último texto escrito pelo filósofo. O filósofo descreve a imagem de um anjo com asas abertas que procura se afastar de algo que ele encara diretamente, como se estivesse assustado.

O anjo da história deve ter esse aspecto. Seu rosto está dirigido para o passado. Onde nós vemos uma cadeia de acontecimentos, ele vê uma catástrofe única, que acumula incansavelmente ruína sobre ruína e as dispersa a nossos pés ${ }^{5}$.

O desejo do anjo é de retornar e juntar todos os fragmentos esparramados no passado histórico. O retorno não é possível, pois um vendaval mantém o seu voo sempre direcionado ao futuro; $O$ anjo não pode recolher suas asas para acolher os destroços que se acumulam ao chão. A tempestade que arrasta $o$ anjo da história em uma marcha ininterrupta ao futuro proeminente chama-se progresso.

A impossibilidade do anjo de escapar da tempestade do progresso é a mesma do sopro que emana da espacialidade cósmica fantasmagórica de Blanqui. O ideal de ventania do progresso arrasta o espírito histórico contemporâneo, enquanto a fantasmagoria nos mantém em uma realidade onírica que nos faz sentir em troca uma brisa que sopra ao longe, onde nada precisa ser feito, pois essa corrente de ar nos carrega para a inevitável novidade do atual. Cada lugar é preenchido incessantemente pela abóbada espectral, em seu cerne tudo aquilo que surge é uma novidade, que é sempre igual, nunca algo novo. Em meio a esse ambiente surge o "homem bárbaro" que deseja inesgotavelmente se renovar, partindo sempre do zero, recria sua existência esperando que coisas grandiosas venham a surgir daí. Esse novo homem que não confia mais na teia de experiências construídas oralmente em tempos imemoriais, não deixa mais os seus rastros, isso pode ser

\footnotetext{
5 BENJAMIN, p: 226, 1996.
}

Paulo Victor de Albuquerque Silva - Mestrando em Filosofia (UECE), Professor efetivo do Município de Fortaleza. Brasileiro, residente em Fortaleza - CE, E-mail: pvictorpv@ hotmail.com 
percebido nas construções de ferro ou de vidro que seguem o ritmo frenético da fabricação atual e são produtos de maquinarias, retirando até os indícios do trabalho manual humano. ${ }^{6}$ Os espaços fantasmagóricos nos sufocam até nos proporcionar o cansaço e a aceitação de um tempo do inferno. Benjamin explanará isso muito bem em seu texto "Experiência e pobreza":

Ao cansaço segue-se o sonho, e não é raro que o sonho compense a tristeza e o desânimo do dia, realizando a existência inteiramente simples e absolutamente grandiosa que não pode ser realizada durante o dia, por falta de forças ${ }^{7}$.

O cansaço se materializa em decorrência dos mais variados elementos comprimidos sob a mesma abóbada fantasmagórica do real, que geram contraditoriamente a sua riqueza de possibilidades, uma inércia que acossa o homem pós-moderno fatigado com a explosão de contrastes informativos que sobrecarregam nossa existência. Em meio a essa explosão de fragmentos cósmicos que se misturam à efemeridade do dia a dia, nos enclausuramos em uma existência de casulo, reproduzindo o sonho mítico dos antigos, em uma vida que basta a si mesma, em um isolamento autossuficiente, psicologicamente e ilusoriamente reconfortante.

A resignação, eivada de melancolia, se torna a marca do homem moderno, algo extremamente preocupante para Walter Benjamin que nos propõe uma filosofia da resistência. O homem da Modernidade encontra-se sob o signo de saturno. Ele "torna os homens apáticos, indecisos. E predispõe ao taedium vitae". Talvez essa predisposição à resignação seja o prenúncio de um estado de ânimo que inaugura o advento do tempo homogêneo e vazio (homogene und leere Zeit), tempo infernal da Modernidade, tempo fantasmagórico, carnavalesco como é designado no ensaio "Experiênca e Pobreza". 9 Devemos acordar dessa "Matrix" fantasmagórica -

\footnotetext{
${ }^{6}$ Raul Seixas, cantor brasileiro, tinha a plena noção de que sonhos que se sonham junto tornam-se realidade, e é exatamente isto o que ocorre na realidade onírica contemporânea.

7 Ibidem, p: 118-119.

${ }^{8}$ CALLADO, "A teoria da melancolia em Walter Benjamin. A versão do taedium vitae medieval e de seus elementos teológicos na concepção de melancolia do barroco" in:__Cadernos Walter Benjamin №8, julhodezembro de 2008, acessível no site: www.gewebe.com.br

${ }^{9}$ Paralelo a esse mundo fantasmagórico surge, meio à profusão de símbolos, e se desenvolve, a sensação de uma perda". CALLADO, Opus cit, p 7. Com certeza Benjamin estaria se referindo, na análise dos símbolos
} 
tomando como referência o filme dos irmãos Wachowski - e para tanto pensar em estratégias de confronto que dissolvam as superestruturas desse fenômeno histórico social, pois até mesmo os críticos revolucionários mais ferrenhos não conseguiram escapar de sua extensão, como foi o caso de Blanqui. "Esta resignação sem esperança é a última palavra do grande revolucionário"10. Quem sabe outro sopro nos sussurre aos ouvidos a vinda de possíveis resistências, com uma tempestade que advenha, não do paraíso, mas de outro mundo, de uma minúscula realidade feérica.

\section{O fenômeno da infância}

Se pensarmos no mundo feérico da criança perceberemos que essas se relacionam com o real através de sua brincadeira. Esta comunicação direta e sem interrupções criança/mundo, é o modo intrínseco que todos os seres vivos encontraram para adentrar na existência efetiva. É através da brincadeira que a criança sai do "estado natural", entendido aqui como um momento "pré-reflexivo", para adentrar na superestrutura social. Essa interação ocorre através da faculdade mimética, pois, enquanto seres afetivos, nos comunicamos com o mundo por meio da habilidade de imitar. Benjamin nos deixa bem claro o modo como a faculdade mimética se revela no jogo infantil em seu texto "A doutrina das semelhanças", quando este afirma que toda a natureza produz semelhanças através da mímica. Nela a criança desenvolve suas primeiras habilidades (físicas e cognoscíveis), sendo portanto, a capacidade genealógica que co-determina nossas funções superiores. "Essa faculdade tem uma história, tanto no sentido filogenético como ontogenético. No que diz respeito ao último, a brincadeira infantil constitui a escola dessa faculdade" ${ }^{\prime 11}$. Para Benjamin a própria matéria traz encravada consigo a história cósmica que pode ser reproduzida na mimese, onde na filogenia a criança brinca de ser médico ou professor, enquanto a ontogenia representaria a memória

dispersos do barroco, aos símbolos que norteiam nossa existência, na Modernidade, do título tão cobiçado à mercadoria oferecida pela lógica do capital.

${ }^{10}$ BENJAMIN, 2009, p. 67.

${ }^{11}$ BENJAMIN, p: 108, 1996.

Paulo Victor de Albuquerque Silva - Mestrando em Filosofia (UECE), Professor efetivo do Município de Fortaleza. Brasileiro, residente em Fortaleza - CE, E-mail: pvictorpv@ hotmail.com 
viva das coisas fenomênicas guardadas na memória pulsante do corpo infantil que imita um trem ou um avião. ${ }^{12}$

$O$ real se revela para a criança em sua abertura para a potência do ato mimético. A potência se manifesta em duas instâncias, no engendrar de semelhanças da própria natureza e na criatividade dos pequeninos seres que se dispõem perante o aberto. A cópia do natural que se manifesta nunca é autêntica, antes é um mesmo que é novo, é um clone singular produzido pela mão do criador infantil. $\mathrm{O}$ clone do jogo ${ }^{13}$ carrega consigo a carga genética da origem histórica e natural, histórica seja filogenética ou ontogenética. O jogo é um artifício, uma fenda na espacialidade do real. Enquanto rachadura ele não está fora da superfície - da lógica do mercado - pelo contrário, está em meio a ela como uma ferida. Dentro desta fenda cabe somente o corpo minúsculo da criança, que constrói com a brincadeira, não uma fantasia irreal, mas a intercomunicação com o fragmento.

O lúdico, em sua efetividade, utiliza de meios ou objetos que manifestam a concretude de sua auto aparição. Mas, antes mesmo de ser um objeto, este instrumento é uma extensão, um prolongamento do membro corporal que chamamos de brinquedo. O brinquedo/extensão é o "qualquer"14 do mundo material que se abre ao imaginário infantil, adentrando nesse mundo através de uma simbiose. O contato direto e limpo com o "qualquer" gera um confronto entre o mundo feérico e o pragmático simbólico amadurecido. $O$ confronto entre criança/adulto não é um choque de gerações diferenciadas, é o encontro criança/história, em que toda a produção da cultura humana acaba nas mãos da pequena entidade que brinca. Sobre esse confronto Benjamin explanará em seu texto "Brinquedos e jogos" o modo como esse se consolida no mundo

\footnotetext{
${ }^{12}$ A relação entre corpo e memória no pensamento benjaminiano se torna bem evidente em seu texto "O narrador", quando o filósofo demonstra as alterações que sofreram a tradição oral e a experiência existencial do homem contemporâneo após as transformações do trabalho, de manufatureiras para industriais, dentro do sistema capitalista de produção, por exemplo. Para mais vide: BENJAMIN, Walter. Magia e técnica, arte e política: ensaios sobre literatura e história da cultura. Tradução de Sérgio Paulo Rouanet. São Paulo: Brasiliense, 1996, p. 197.

${ }^{13}$ Tomemos a liberdade de esclarecer que quando utilizamos a palavra "jogo" estamos nos referindo à "brincadeira", tendo em vista uma maior variação de termos, pois reconhecemos que o conceito de "jogo" e "brincadeira" são totalmente distintos no pensamento benjaminiano.

${ }^{14}$ A ideia de "qualquer" ao qual estamos dispostos a desenvolver, não tem referência com o conceito de Giorgio Agamben, em sua obra "A comunidade que vem". O "qualquer" por nós proposto é relativo tanto a corporeidade da criança quanto a abertura dos objetos que estão disponíveis ao seu manuseio lúdico.
} 
material/histórico, defendendo que a percepção infantil se manifesta coberta pelos vestígios das gerações a ela predecessoras, em um encontro que por vezes não é amigável.

O brinquedo, mesmo quando não imita os instrumentos dos adultos, é confronto, e, na verdade, não tanto da criança com os adultos, mas destes com a criança. Pois, quem, senão o adulto fornece primeiramente à criança os seus brinquedos? ${ }^{15}$.

Para o filósofo o fenômeno feérico jamais poderá realizar-se em um ideal de infância ou arte pura, já que se encontra submerso em meio aos objetos históricos materiais da existência humana, carregados com sua filogenia e ontogenia.

Então, quais são as regras do "jogo de confrontos" entre a criança e o mundo? É evidente que ao pensarmos em regras para a esfera lúdica da infância é o mesmo que blasfemar, mas o que seria o brincar se não uma profanação, no sentido religioso do mito, que a modernidade realiza, uma desconstrução dos valores enraizados nas entranhas da moral humana. A criança é um ser "extemporâneo", é um fora/dentro da historia viva, onde tudo o que ela toca não se transforma em ouro, mas ganha um teor de extemporaneidade, passa também a ser um dentro/fora na historicidade. Nesse sentido, o brinquedo não é um "Outro", mas uma extensão fisiológica do seu corpo, e na mesma medida em que damos maior ou menor atenção aos órgãos que nos compõe, as crianças se debruçam sobre as coisas do mundo ou da natureza carregando-as para a "realidade feérica". Através do pensamento filosófico conhecemos as realidades conceituadas por "natureza", enquanto aquilo que não sofreu a alteração humana, de "mundo", como sendo tudo aquilo proveniente do espírito. Agora, por meio da ludicidade vemos surgir o "feérico", uma realidade própria com suas "regras", seu "tempo", sua "espacialidade".

(...) não poucos dos mais antigos brinquedos (bola, arco, roda de penas, pipa) terão sido de certa forma impostos à criança como objetos de culto, os quais só mais tarde, e certamente graças à força da imaginação infantil, transformaram-se em brinquedos ${ }^{16}$.

\footnotetext{
${ }^{15}$ BENJAMIN, p: 96, 2009

${ }^{16}$ Ibidem, p: 96.
} 
Não esqueçamos que estamos nos referindo a um confronto. O jogo infantil é uma afronta entre a "natureza", o "mundo" e o "feérico", todos dentro de uma imanência histórica. Para brincar basta acoplar o algo mais infantil que se revela ao seu corpo.

O jogo infantil sempre se manifesta da mesma maneira no decorrer da história humana? Se pensarmos que a brincadeira detém como primeiro motor a faculdade mimética e que esta ultima, enquanto projeção do real, sempre coaduna com os devires do mundo fenomênico, então podemos concluir que a ludicidade infantil altera-se com o passar dos tempos. O jogo nunca é o mesmo, ele é um eterno retorno do diferente. Sabemos que nada deixa uma criança mais feliz do que brincar novamente, mas a cada "repetição" existe uma nova desconstrução do dado, uma ressignificação do real que nos leva a perceber as etapas ao qual o objeto foi decomposto. Se pensarmos nessa manifestação em uma escala histórica observaremos que o ato de brincar é, antes de tudo, um confronto direto com todas as conjecturas simbólico/linguísticas em tempos e espaços diferenciados. Essa desconstrução do real revela que a ação lúdica da criança não se caracteriza como um ato restritamente passivo, já que nos referimos à faculdade mimética enquanto um processo de reprodução, antes detém uma atitude altamente criativa e inovadora, potente. A infância é a efetivação de um ser criativo que se utiliza uma mobilidade desconstrutiva para em sequência construir um novo mundo à sua maneira, através de sua imaginação. Vale salientar que a ação lúdica daquele que brinca desponta de maneira totalmente despretensiosa, longe, por exemplo, de uma finalidade ética ou política, sendo majoritariamente livre, em uma ação que basta a si mesma, onde inexiste qualquer vestígio da vivência de um sujeito do conhecimento, tal como reconhecido pela tradição filosófica. Não pensemos que o bastar a si mesmo seja um isolamento, tudo é redimido e acolhido para dentro do jogo formulando um microcosmo que detém todos os caracteres do macrocosmo, como uma mônada: "há portanto um grande equívoco na suposição de que são simplesmente as próprias crianças, movidas pelas suas necessidades, que determinam todos os brinquedos. É um desatino quando uma obra recente, no mais bastante meritória, acredita por exemplo poder explicar a matraca do bebê com a afirmação: 'por regra geral, a audição é o primeiro sentido a exigir atividade' - 
desatino porque desde tempos remotos o chocalho é um instrumento de defesa contra os maus espíritos, o qual justamente por isso deve ser colocado nas mãos do recém-nascido. ${ }^{17}$,

O chocalho ao qual Benjamin se refere na ultima citação aqui exposta somente se transforma em um objeto lúdico quando entra em contato com a criatividade infantil. Ressaltamos que os signos presentes no "mundo" pragmático dos adultos por vezes escapam à esfera feérica, pois neste último reino a criança é o seu senhor soberano e inalienável. A abertura do real em face do jogo tem de ser compatível com a dimensão do corpo da pequena entidade que se dispõe sobre o algo mais infantil, isso nos ajuda a compreender a preferência da criança por objetos pequenos, pois são fáceis na manipulação lúdica. Tendo em vista a extensão corporal, Benjamin explanará em sua obra "Rua de mão única" um fragmento em que a criança se depara com os restos de uma construção afirmando:

Nesses produtos residuais elas reconhecem o rosto que o mundo das coisas volta exatamente para elas, e somente para elas. (...) Com isso as crianças formam o seu próprio mundo de coisas, um pequeno mundo inserido no grande ${ }^{18}$.

Portanto, deveríamos ter em mente a capacidade genuinamente criativa da criança em sua construção arquitetônica despretensiosa, que não necessita das frequentes intervenções dos adultos em uma frustrada tentativa de guiar o jogo infantil, já que a sua mente inventiva sempre escapará das amarras do caduco simbolismo pragmático.

Reconhecendo as mais variadas manifestações da brincadeira ao longo de nossa história cabe-nos perguntar: De que maneira o ato/potência infantil contribui para uma reflexão filosófica em torno do fenômeno da metrópole pensada por Walter Benjamin?

\section{Brincando com a metrópole}

Ao nos depararmos com a ludicidade infantil somos sumariamente arremessados ao encontro com todos os fenômenos materiais de nossa existência, sejam eles produtos do espírito ou mesmo da natureza. Na sociedade pós-moderna

\footnotetext{
17 Ibidem, p: $96-97$.

18 lbidem, p: 104.

Paulo Victor de Albuquerque Silva - Mestrando em Filosofia (UECE), Professor efetivo do Município de Fortaleza. Brasileiro, residente em Fortaleza - CE, E-mail: pvictorpv@ hotmail.com
} 
a materialidade é totalmente envernizada pelo aparato fantasmagórico, que suprime o corpo e a alma de seus habitantes. Neste sentido, as argúcias espectrais da metrópole estabelecem fronteiras territoriais onde sua magia pode ser efetivada e nada poderá escapar de seu radar. Sabe-se que a única possibilidade de se escapar do raio de ação de um radar seria sobrevoando abaixo de seus sensores. É exatamente isso o que ocorre com a brincadeira infantil em relação aos espaços fantasmagóricos, ela se manifesta abaixo do seu raio de alcance, a criança foge da identificação toda vez que brinca, pois ela se transporta para o lúdico mundo do feérico. $O$ ato de brincar projeta-se como uma ação de resistência as estruturas formuladas pelo "espírito do tempo" (Zeitgeist) na medida em que cria novas espacialidades/temporalidades para além do arcabouço fantasmagórico, dotando a realidade de novas significações, que por sua vez nunca se fecham, mas que se encontram abertas a capacidade da criatura de nomear ${ }^{19}$. Através da faculdade mimética as crianças comunicam-se com o mundo doando-lhe novos sentidos singulares que ultrapassam os limites espectrais. "A criança quer puxar alguma coisa e torna-se cavalo, quer brincar com areia e torna-se padeiro, quer esconder-se e torna-se bandido ou guarda." ${ }^{20}$. O fato de puxar as coisas, como exposto aqui por Benjamin, significa capturá-las para dentro da realidade feérica.

Quando questionamos a temporalidade do inferno produzida pelo capital, esta também encontra-se distorcida dentro do ambiente lúdico. Para representarmos essa imagem podemos utilizar como referência a pintura "A persistência da memória" de Salvador Dali, em que se encontram relógios derretidos que expressam a relatividade do tempo, no nosso caso quando remetidos à esfera lúdica. Pensar o tempo do jogo é ter em mente a sua ideia de repetição, que nesse caso não se materializa enquanto o eterno retorno do mesmo, como novidade do capital, antes é afirmar o diferente, a singularidade dos atos repetidos que nunca são idênticos. $O$ espaço/tempo fantasmagórico é substituído pelo espaço/tempo feérico da infância.

\footnotetext{
${ }^{19}$ Para aqueles que desejarem compreender melhor a capacidade nomeadora da criatura, ou seja, a linguagem adâmica, vide o texto "Sobre a linguagem em geral e sobre a linguagem do homem", que discorrerá acerca da questão da linguagem enquanto elemento nomeador de todo ente criado por Deus.

20 BENJAMIN, p: 93, 2009.
} 
Neste instante somos acometidos pela imagem do "Anjo da História" de asas abertas sem poder retornar aos fragmentos do passado que se acumulam aos seus pés, onde uma força o empurra rumo ao horizonte, inviabilizando o seu intuito de salvaguardar o que ficou para trás. A criança, por sua vez, não possui asas e por isso pode redimir todo o bem material produzido pela humanidade, sem nenhuma distinção, até levá-los ao miraculoso mundo da terra do nunca da infância. Neste sentido, nem mesmo as estruturas fantasmagóricas que sustentam a ideia de progresso da humanidade resistem à demolição ocasionada pela brincadeira, que em seu ato desconstrói os ambientes simbolicamente pré-fabricados. Em sua obra "Infância berlinense: 1900", Benjamin descreve suas férias de verão em Potsdam, recordando as conquistas territoriais de sua meninice.

Poder-se-ia ter escrito a história do meu império, que durava desde a minha investidura num dia de verão até à queda desse reino no fim do outono. $E$ toda a minha existência se esgota nas lutas por esse reino $(\ldots)^{21}$.

Qualquer coisa pode ser capturada para dentro do reino infantil, de modo despretensioso, exaltando cada fragmento através de sua iluminação profana ${ }^{22}$, a verdadeira apocatástase ${ }^{23}$ histórica, o verdadeiro estado de exceção em que o soberano detém o poder de decisão sobre o destino histórico da humanidade. Este soberano é a criança que contém em suas mãos o cetro/brinquedo que resiste às fantasmagorias da metrópole, mesmo que de forma despretensiosa e inconsciente.

\footnotetext{
${ }^{21}$ BENJAMIN, p: 93, 2013.

${ }^{22}$ Acerca da iluminação profana irá afirmar Leandro Konder: "A 'iluminação religiosa' deixa o sujeito numa postura passiva; é preciso ir além da passividade, da abstratividade. 'Porém a superação autêntica e criadora da iluminação religiosa não se dá através do narcótico. Ela se dá numa iluminação profana, de inspiração materialista e antropológica."' (KONDER, p: 43, 1988). Sob essa perspectiva que vislumbra a iluminação profana como tendo uma fonte de inspiração materialista e antropológica, enfatizamos a ideia da brincadeira infantil enquanto mais uma fonte de iluminação profana, já que é pertencente aos dois horizontes anteriormente expostos, tanto materialista quanto antropológico.

${ }^{23}$ Apocatastasis = a "a admissão de todas as almas no Paraíso". Para mais, vide os cadernos N na obra "Passagens". BENJAMIN, Walter. Passagens. Tradução de Irene Aron. Tradução do francês de Cleonice Paes Barreto Mourão. Belo Horizonte: Editora UFMG, 2009.
} 


\section{REFERÊNCIAS}

AGAMBEN, Giorgio. A comunidade que vem. tradução de Cláudio Oliveira. Belo Horizonte: Autêntica Editora, 2013.

BENJAMIN, Walter. Escritos sobre mito e linguagem. Tradução de Susana Kampff Lages e Ernani Chaves. São Paulo: Editora 34, 2011.

Magia e técnica, arte e política: ensaios sobre literatura e história da cultura. Tradução de Sérgio Paulo Rouanet. São Paulo: Brasiliense, 1996.

. Passagens. Tradução de Irene Aron. Tradução do francês de Cleonice Paes Barreto Mourão. Belo Horizonte: Editora UFMG, 2009.

Reflexões sobre a criança, o brinquedo e a educação. Tradução de Marcus Vinicius Mazzari. São Paulo: Editora 34, 2009.

Rua de mão única: Infância berlinense: 1900. Tradução de João Barrento. Belo Horizonte: Autêntica Editora, 2013.

CALLADO, Tereza de Castro. A Experiência da Origem, Fortaleza: Eduece, 2006.

CALLADO, Tereza de Castro. A teoria da melancolia In: Cadernos Walter Benjamin N. 01. Julho-dezembro de 2008, acessível no site www.gewebe.com.br

KONDER, Leandro. Walter Benjamin: o marxismo da melancolia. Rio de Janeiro: Campus, 1988.

PERNIOLA, Mario. O sex appeal do inorgânico. Tradução de Nilson Moulin. São Paulo: Studio Nobel, 2005. 